www.jmscr.igmpublication.org

Impact Factor (SJIF): 6.379

Index Copernicus Value: 71.58

ISSN (e)-2347-176x ISSN (p) 2455-0450

crossref DOI:_https://dx.doi.org/10.18535/jmscr/v6i5.29

\author{
Journal Of Medical Science And Clinical Research \\ IGM Publication \\ An Official Publication of IGM Publication
}

\title{
Trends in Prescribing Pattern of Antihypertensives and its Adherence among Post-Menopausal Women with Hypertension in a Tertiary Care Teaching Hospital
}

\author{
Authors \\ Dr Chinnusamy $K^{1}$, Thangamani. $S^{2}$, Sajini $S^{3}$, Sajith Kumar $K^{3}$, Lovin Kurian \\ ${ }^{1}$ Associate Professor, Department of General Medicine, Karuna Medical College Hospital, Palakkad \\ ${ }^{2}$ Assistant Professor, Department of Pharmacy Practice, Grace College of Pharmacy, Palakkad \\ ${ }^{3}$ Pharm D Interns, Department of Pharmacy Practice, Grace College of Pharmacy, Palakkad \\ Corresponding Author \\ Dr Chinnusamy K
}

Phone: 8838826058, Email: chinnusamykaliannan68@gmail.com

\begin{abstract}
Introduction: Menopause is a physiological event that can be defined as the cessation of menstrual cycles for 12 consecutive months, although many women seek medical advice before this time because of the onset of menopausal symptoms. The prevalence of hypertension $(H T)$ is lower in premenopausal women than in men, whereas in postmenopausal women it is higher than in men. The aim of the present study was to identify the prevalence of hypertension and the impact of oral antihypertensives among post-menopausal women.
\end{abstract}

Methodology: A prospective observational study was conducted in General Medicine OPD \& IPD at Karuna Medical College, Vilayodi, Chittur, for a period of 6 months. The study is based on the data collected from 116 patients who were post-menopausal women visiting for the treatment of hypertension.

Result \& Discussion: A total of 116 post-menopausal women with hypertension were included in the study. Prescribing pattern of drugs in post-menopausal women is more complicated than in pre-menopausal women. The commonly prescribed anti-hypertensive agent is Calcium channel blocker (CCB)(45.16\%), followed by Diuretics (19.35\%), Angiotensin receptor blockers (ARB) (14.51\%), Beta blockers (9.67\%) and Angiotensin converting enzyme inhibitors (58\%). In monotherapy, ARB and CCB women achieved significant reduction of $B P$ and in combination therapy $A R B$ with Diuretics gave significant reduction.

Conclusion: In post-menopausal women most commonly prescribed oral anti-hypertensive drugs are calcium channel blockers \& diuretics. It is evident that good adherence to therapy and regular checkups will protect the post-menopausal women with HT from other major complications.

Keywords: Post-Menopausal Women, Hypertension, Adherence.

\section{Introduction}

Menopause is a physiological event that can be defined as the cessation of menstrual cycles for 12 consecutive months, although many women seek medical advice before this time because of the onset of menopausal symptoms. Eighty per cent of women experience vasomotor symptoms, which can be distressing and embrassing. ${ }^{1}$ Hypertension known as high or raised blood pressure, is a global public health issue and the prevalence of 
hypertension is lower in premenopausal women than in men, whereas in 'postmenopausal women it is higher than in men and $41 \%$ postmenopausal women becoming hypertensive worldwide, $25 \%$ of post-menopausal women are hypertensive more than $75 \%$ of women older than 60 years of age. ${ }^{2}$

Prevalence approaches $60 \%$ in post-menopausal women older than 45 years. Hypertension is largely because of progressive arterial stiffening and abruptly falling estrogen levels, which in turn activate the renin-angiotensin-aldosterone and sympathetic nervous systems. Endothelial dysfunction is considered to be one of the mechanisms by which estrogen deficiency may result in hypertension. ${ }^{3}$

The drug prescription in menopause is complex and many factors such as polypharmacy, comorbid conditions, pharmacokinetic and pharmacodynamic variability, and noncompliance make this group a high risk as far as drug safety is concerned. Although studies are available analyzing prescription trends about antihypertensives across various age groups from western and Indian setup, there is no single study available in the literature regarding prescription trends and rationality of anti-hypertensive drugs among Indian postmenopausal women. ${ }^{4,5}$ It is difficult to know the disease specific values among post-menopausal women. So in our study we are analyzing prescribing pattern of antihypertensive drugs, adherence to the treatment guidelines and its impact on blood pressure level among the post-menopausal women.

\section{Methodolgy}

An observational study was conducted in the Department of General Medicine at Karuna Medical College Hospital, Palakkad for a period of 6 months. Approval of the Institutional Ethical committee was obtained prior to commencement of the study. Inclusion criteria: Post-menopausal women with hypertension. Exclusion criteria: Post-menopausal women who had undergone hysterectomy, oophorectomy. Data collection forms were prepared as a tool for collection of data like demographic profile, past medication history, family history, age of menopause. Some clinical and therapeutic data such as initial systolic blood pressure (SBP), diastolic blood pressure (DBP) and antihypertensive drugs were extracted from the case file of the patients. The BP values were collected again during the next two visits. The level of adherence with the therapy was assessed by using MMAS-8 scale in the reviews. $\mathrm{P}$ value $<0.05$ was considered to be statistically significant.

\section{Results \& Discussion}

A total of 116 patients met the inclusion criteria. At 6 months following initiation, follow-up data were available on all (100\%) of these patients. The baseline characteristics of study population are shown in Table 1 and of these, 103 (88.7\%) patients are of $\geq 45 \mathrm{yrs}$ of age. $50 \%$ of postmenopausal women had cardio vascular disease and cerebro vascular disease and the average duration of hypertension was more than five years.

In the present study, the most commonly prescribed anti-hypertensive agent is Calcium channel blocker (CCB) (45.16\%), followed by Diuretics (19.35\%), Angiotensin receptor blockers (ARB) (14.51\%), Beta blockers (9.67\%) and Angiotensin converting enzyme inhibitors (58\%). Monotherapy was prescribed with 62 patients and combination with 54 patients. CCB was predominant in both therapy because it has protective role in the prevention of postmenopausal women from dementia and osteoporosis. According to JNC-8 Guidelines, it is recommended that Diuretics and Calcium channel blockers are effective drug classes for treating hypertension in patients more than 45 years of age.

The impact of monotherapy for patients is showed in Table 2. Among 62 patients CCB was prescribed in 28 patients (45\%), Diuretics in 12 patients (19\%), ARB in 9 patients (15\%), ACE inhibitors in 7 patients $(11 \%)$ and Beta blocker in 6 patients (10\%). Among these, CCB reduced the BP level in both reviews significantly $(P \leq 0.0001)$. 
Hence $\mathrm{CCB}$ is an effective monotherapy for postmenopausal women.

The various drug combinations used in therapy among study population is shown in Table-3. Among these Telmisartan + Hydrochlorthiazide was prescribed in 22 patients $(41 \%)$, Amlodipine +Atenolol in 15 patients (28\%), Metoprolol + Losartan in 10 patients (19\%) and Losartan + Hydrochlorthiazide in 7 patients (13\%). Telmisartan + Hydrochlorthiazide therapy significantly reduced the BP level in both reviews. It indicates ARB with Diuretics is the most commonly prescribed combination therapy and it has the beneficial effect of reducing BP level in post-menopausal women.

The level of adherence was evaluated by using MMAS-8 Scale among study population. Out of 116 patients, the medium level of adherence was seen in 77 patients (66\%), low level of adherence was seen in 21 patients (18\%) and high level of adherence in 18 patients $(16 \%)$. The impact of level of adherence on BP level was analyzed. In this study, patients with high and medium level of adherence showed statistically significant reduction in BP level in review 2. It showed patients need maximum adherence with the therapy for best outcome.

Table: 1 Demographic profile of study

\begin{tabular}{|lc|}
\hline PARAMETERS & \\
\hline $\begin{array}{l}\text { Age n (\%) } \\
\quad \leq 45 \text { yrs }\end{array}$ & $13(11.2 \%)$ \\
$\quad \geq 45$ yrs & $103(88.7 \%)$ \\
\hline Co-Morbidities n (\%) \\
Cardiovascular disease & $39(33.6 \%)$ \\
Cerebrovascular disease & $\mathbf{2 6}(22.4 \%)$ \\
Kidney disease & $13(11.2 \%)$ \\
Others & $\mathbf{3 8}(32.7 \%)$ \\
\hline Family H/O hypertension n (\%) & $\mathbf{5 3 ( 4 5 . 6 \% )}$ \\
\hline Duration of Hypertension (mean \pm SD) & $\mathbf{5 . 2 \pm 4}$ \\
\hline
\end{tabular}

Table: 2 Impact of monotherapy of oral Anti-hypertensive drugs in Blood pressure among study populations

\begin{tabular}{|c|c|c|c|}
\hline Monotherapy $(n=62)$ & $\begin{array}{l}\text { Baseline } \\
(\text { Mean } \pm \text { SD })\end{array}$ & $\begin{array}{l}\text { Review } 1 \\
(\text { Mean } \pm \text { SD) }\end{array}$ & $\begin{array}{l}\text { Review } 2 \\
(\text { Mean } \pm \text { SD) }\end{array}$ \\
\hline Diuretics (n=12) & \multirow[b]{2}{*}{$133.3 \pm 25.3$} & \multirow[b]{2}{*}{$126.6 \pm 11.54^{\mathrm{ns}}$} & \multirow[b]{2}{*}{$115.83 \pm 6.68 * *$} \\
\hline Systolic BP (mmHg) & & & \\
\hline Diastolic BP (mmHg) & $94.18 \pm 9.9$ & $85.83 \pm 5.14^{\mathrm{ns}}$ & $74.58 \pm 4.98 * * * *$ \\
\hline CCBs $(n=28)$ & \multirow[b]{2}{*}{$162.5 \pm 21.01$} & \multirow[b]{2}{*}{$132.14 \pm 18.1 * * * *$} & \multirow[b]{2}{*}{$112.1 \pm 7.86^{* * * * *}$} \\
\hline Systolic BP (mmHg) & & & \\
\hline Diastolic BP (mmHg) & $94.64 \pm 6.92$ & $81.78 \pm 10.2 * *$ & $72.85 \pm 7.12 * * * *$ \\
\hline ACE Inhibitors (n=7) & \multirow[b]{2}{*}{$137.14 \pm 9.5$} & \multirow[b]{2}{*}{$132.85 \pm 13.8^{\mathrm{ns}}$} & \multirow[b]{2}{*}{$128.5 \pm 6.9^{\mathrm{ns}}$} \\
\hline Systolic BP (mmHg) & & & \\
\hline Diastolic BP (mmHg) & $82.8 \pm 4.87$ & $79 \pm 4.49^{\mathrm{ns}}$ & $74.28 \pm 5.34^{\mathrm{ns}}$ \\
\hline ARBs $(n=9)$ & \multirow[b]{2}{*}{$146.6 \pm 15$} & \multirow[b]{2}{*}{$130 \pm 10 * * *$} & \multirow[b]{2}{*}{$124.4 \pm 5.27 * * * *$} \\
\hline Systolic BP (mmHg) & & & \\
\hline Diastolic BP (mmHg) & $81.11 \pm 6$ & $78.8 \pm 6^{\mathrm{ns}}$ & $73.3 \pm 5^{\mathrm{ns}}$ \\
\hline Beta Blockers $(n=6)$ & \multirow[b]{2}{*}{$140.8 \pm 20$} & \multirow[b]{2}{*}{$136.6 \pm 15.05^{\mathrm{ns}}$} & \multirow[b]{2}{*}{$130 \pm 12.64^{\mathrm{ns}}$} \\
\hline Systolic BP (mmHg) & & & \\
\hline Diastolic BP (mmHg) & $83.3 \pm 8.16$ & $80 \pm 8.94^{\text {ns }}$ & $78.33 \pm 7.52^{\mathrm{ns}}$ \\
\hline
\end{tabular}


Table: 3 Impact of Combination therapy of oral Anti-hypertensive drugs in Blood pressure among study populations

\begin{tabular}{|c|c|c|c|}
\hline Type of therapy & $\begin{array}{c}\text { Baseline } \\
(\text { Mean } \pm \text { SD })\end{array}$ & $\begin{array}{c}\text { Review } 1 \\
(\text { Mean } \pm \text { SD) }\end{array}$ & $\begin{array}{c}\text { Review } 2 \\
(\text { Mean } \pm \text { SD) }\end{array}$ \\
\hline \multicolumn{4}{|c|}{ Telmisartan + Hydrochlorthiazide $(n=22)$} \\
\hline Systolic BP (mmHg) & $164.09 \pm 24.81$ & $128.63 \pm 16.70^{* * * *}$ & $108.18 \pm 5.01 * * * *$ \\
\hline Diastolic BP (mmHg) & $100.9 \pm 7.50$ & $82.72 \pm 9.35^{* * * * *}$ & $72.27 \pm 4.28 * * * *$ \\
\hline \multicolumn{4}{|c|}{ Metoprolol + Losartan $(n=10)$} \\
\hline Systolic BP (mmHg) & $130 \pm 26.60$ & $122 \pm 13.98^{\mathrm{ns}}$ & $118 \pm 7.8^{\mathrm{ns}}$ \\
\hline Diastolic BP (mmHg) & $93 \pm 10.5$ & $80 \pm 9.71^{\text {ns }}$ & $76 \pm 5.16^{*}$ \\
\hline \multicolumn{4}{|c|}{ Amlodipine +Atenolol $(n=15)$} \\
\hline Systolic BP (mmHg) & $132 \pm 17.8$ & $129.3 \pm 14.09^{\mathrm{ns}}$ & $120.6 \pm 2.5^{*}$ \\
\hline Diastolic BP (mmHg) & $92.6 \pm 10.9$ & $80.6 \pm 5.9 *$ & $72.9 \pm 4.5 * * * *$ \\
\hline \multicolumn{4}{|c|}{ Losartan + Hydrochlorthiazide (n=7) } \\
\hline Systolic BP (mmHg) & $137.1 \pm 7.5$ & $130 \pm 5.7^{\mathrm{ns}}$ & $120 \pm 3.77 * * * *$ \\
\hline Diastolic BP (mmHg) & $98.5 \pm 6.9$ & $82.8 \pm 4.8 * * * *$ & $71.8 \pm 3.7 * * * *$ \\
\hline
\end{tabular}

Table: 4. Impact of level of adherence (MMAS-8 Scale) in Blood Pressure among study population

\begin{tabular}{|c|c|c|c|}
\hline Level of adherence & $\begin{array}{c}\text { Baseline } \\
(\text { Mean } \pm \text { SD })\end{array}$ & $\begin{array}{c}\text { Review } 1 \\
(\text { Mean } \pm \text { SD })\end{array}$ & $\begin{array}{c}\text { Review } 2 \\
(\text { Mean } \pm \text { SD })\end{array}$ \\
\hline \multicolumn{4}{|l|}{ High $(n=18)$} \\
\hline Systolic BP (mmHg) & $133.3 \pm 10.84$ & $128.8 \pm 11.31^{\mathrm{ns}}$ & $121.66 \pm 7.07 * * *$ \\
\hline Diastolic BP (mmHg) & $81.6 \pm 9.85$ & $80.8 \pm 6.47^{\mathrm{ns}}$ & $74.88 \pm 6.10^{\mathrm{ns}}$ \\
\hline \multicolumn{4}{|l|}{ Medium (n=77) } \\
\hline Systolic BP (mmHg) & $138.15 \pm 20.5$ & $132.3 \pm 18.06^{*}$ & $124.1 \pm 13.8^{* * * *}$ \\
\hline Diastolic BP (mmHg) & $84.54 \pm 11.45$ & $80.5 \pm 9.76^{\text {ns }}$ & $77.7 \pm 8.2 * * *$ \\
\hline \multicolumn{4}{|l|}{ Low $(n=21)$} \\
\hline Systolic BP (mmHg) & $138.1 \pm 18.67$ & $126.3 \pm 14.32 *$ & $119.5 \pm 18.3^{*}$ \\
\hline Diastolic BP (mmHg) & $85 \pm 9.12$ & $79.7 \pm 7.39^{\mathrm{ns}}$ & $75 \pm 8.2^{\mathrm{ns}}$ \\
\hline $\begin{array}{l}\text { ns- Non significant P>} \\
\text { Baseline Blood Pressure }\end{array}$ & $P \leq 0.05$, * & $1, * * *_{-} P \leq 0.00$ & $P \leq 0.0001$ Versus \\
\hline
\end{tabular}

\section{Conclusion}

Menopause has an unfavorable effect on metabolism and hormones, thus is likely to be responsible for increased incidence of hypertension with advancing age after 40 years. This study reveals that monotherapy was prescribed more than combination therapy among postmenopausal women. Most commonly prescribed mono therapy is Calcium channel blockers (Amlodipine) followed by ARBs (Sartans), as these drugs have protective role in osteoporosis, dementia and diabetics among postmenopausal women. Among combination therapies, ARBs and diuretics was most commonly prescribed and is effective in reducing the BP levels.

\section{Source of support: Nil}

\section{Reference}

1. Mirza A, Shaktibala D, Amit V, Ravi K et al. A study on drug prescribing pattern in hypertensive patients in a tertiary care teaching hospital at Dehradun, Uttarakhand. International journal of medical science and public health, 2014, 170420146.

2. Vishal RT, Sudhaa S, Shagun M et al. Antihypertensive drug prescription patterns, rationality, and adherence to Joint National Committee-7 hypertension treatment guidelines among Indian postmenopausal women. J Midlife Health, 2014, 10.4103/09767800.133994. 
3. Nimmy $N$, Mohan $R$, Narmadha MP. Assesment of cardiovascular risk in pre and post-menopausal hypertensive women. IRJP, 2012, (3)7.

4. Shpana S, Kaiser H, Sumon R et al. Assesment of prescription pattern of hypertensives patient's prescription; A prescription based survey from various hospitals of Bangladesh.

5. Kapoor B, Raina RK, Kapoor S. Drug prescribing pattern in a teaching hospital. Indian Journal of Pharmacology, 1985, 17, 168.

6. Pradhan SC, Shewade DG, Shashindran $\mathrm{CH}$, Bapna JS. Drug utilization studies. National Medical Journal of India, 1988, 1, 185.

7. Divya G, Rekha D, Lakshmi P et al. Prescribing Patterns of Antihypertensive Drugs in Cardiology Department. Inventi Rapid: Pharmacy Practice, 2014, 09763848.

8. Nisha R, Nelta S, Gomathi S. A prospective study of prescribing pattern of antihypertensive drugs. IJPAR, 2015, 2320-2831. 10. Noah J, Narasinga R, Jagannadha $\mathrm{R}$ et al.

9. A review on prescribing patterns of antihypertensive drug. Clinical Hypertension, 2016, 22, 7, 40885-016-0042. 